\title{
CRAS Itinerante: uma proposta de busca ativa, territorial, descentralizada e interdisciplinar
}

Bruno Ricardo Bérgamo Florentino', Angra dos Reis Florentino²

\begin{abstract}
Resumo
Com as constantes e recentes transformações no campo das políticas sociais brasileiras, a expansão da unidade estatal denominada Centro de Referência de Assistência Social (CRAS) por todo o país e os diferentes atores da política de assistência - sobretudo os gestores e profissionais - buscam, cada vez mais, a implantação de estratégias técnico-operativas que permitam cumprir os objetivos propostos pela proteção social básica da Política Nacional de Assistência Social. Nesse sentido, o presente texto consiste no relato de experiência de um projeto intitulado "CRAS Itinerante"; uma proposta de busca ativa que ocorreu logo após o lançamento do Plano Brasil Sem Miséria, no município de Coronel Xavier Chaves, Minas Gerais. Assim, destacamos as diretrizes e as orientações do Ministério do Desenvolvimento Social (MDS), fazemos uma breve contextualização do município, dos detalhes da estratégia metodológica empregada para a realização do projeto e apresentamos os principais resultados obtidos.
\end{abstract}

\section{Palavras-chave}

CRAS Itinerante. Busca Ativa. Território. Descentralizado. Comunidade.

1. Mestre em Psicologia pela Universidade Federal de São João Del Rei, Secretario Municipal de Assistência Social de Coronel Xavier Chaves-MG, colaborador técnico especializado do Grupo Cultural Consciência Negra de Coronel Xavier Chaves-MG. E-mail: bruno_psicologia@hotmail.com.

2. Graduada em Pedagogia pela Universidade Estadual Paulista "Júlio de Mesquita Filho", coordenadora do Centro de Referência de Assistência Social (CRAS) de Resende Costa-MG. E-mail: angra_pedagogia@hotmail.com. 


\title{
CRAS Itinerante: a proposal for an active territorial, decentralized and interdisciplinary search
}

Bruno Ricardo Bérgamo Florentino*, Angra dos Reis Florentino**

\begin{abstract}
According to the constant and recent changes in the social politics field in Brazil, the expansion throughout the country of the state unit called Reference Centre for Social Welfare (Centro de Referência de Assistência Social - CRAS) and the different participants in the public service - particularly managers and professionals - increasingly seeks for the implementation of technical and operational methodologies that enable them to fulfill the objectives proposed by the basic social protection of the National Politics for Social Welfare (Política Nacional de Assistência Social). Thereby, this text is an experience report made from a project entitled "CRAS Itinerante" (Itinerant CRAS), which is a proposal for an active search that was brought forward shortly after the launching of the Brazil Without Extreme Poverty Plan, in Coronel Xavier Chaves, Minas Gerais state. Thus, we highlight the policies and guidelines of the Ministry of Social Development (MSD), make a brief overview of the city and the details of the methodological strategy employed during the project and we also present the main research results.
\end{abstract}

\section{Keywords}

CRAS Itinerante. Active Search. Territory. Descentralized. Community.

\footnotetext{
* Master in Psychology from the Federal University of São João Del Rei, Municipal Secretary of Social Assistance in Coronel Xavier Chaves, Minas Gerais state, specialized technical collaborator of the Black Consciousness Cultural Group of Coronel Xavier Chaves, Minas Gerais state. E-mail: bruno_psicologia@hotmail.com.

** Graduated in Pedagogy from the São Paulo State University "Julio de Mesquita Filho", coordinator at Reference Centre for Social Welfare (CRAS) of Resende Costa, Minas Gerais state. E-mail: angra_pedagogia@hotmail.com.
} 


\section{Introdução}

A Lei Orgânica de Assistência Social (LOAS), como desdobramento da Constituição Federal de 1988, alavancou toda uma discussão sobre a formulação e a implantação de um sistema público descentralizado, que acabou culminando na atual Política Nacional de Assistência Social (PNAS) e no Sistema Único de Assistência Social (SUAS) - sistematizado pelo Ministério do Desenvolvimento Social (MDS) e materializado por meio das equipes que atuam nos equipamentos públicos de proteção social básica e especial dos estados e municípios de todo o país.

O processo de implantação e expansão da PNAS e do SUAS, sob o paradigma da constituição do direito socioassistencial, ao invés do modelo assistencialista, incidiu e ainda incide em questões fundamentais e substantivas para a gestão do trabalho e dos trabalhadores que compõem a equipe de profissionais do SUAS. Nesse sentido,

a assimilação por todos os atores envolvidos com a Política Pública de Assistência Social (gestores, servidores públicos, trabalhadores das entidades e organizações sem fins lucrativos, conselheiros, entre outros) é ainda um desafio a enfrentar. (BRASIL, 2006, p. 9).

Lopes (2006) destaca que o SUAS representa a possibilidade de unificação das ações da assistência social de forma que elas possam ser geridas a partir de algumas diretrizes nacionais e, ao mesmo tempo, respeitar as características, diversidades e condições locais do município, garantindo, assim, o caráter universal de garantia de direitos individuais e coletivos.

A proteção social básica, considerada a porta de entrada de um sujeito na política de assistência social, é materializada no Centro de Referência de Assistência Social (CRAS), que se apresenta como possibilidade de prevenir

[...] situações de risco por meio do desenvolvimento de potencialidades e aquisições, e o fortalecimento de vínculos familiares e comunitários. Destina-se à população que vive em situações de vulnerabilidade social decorrente da pobreza, privação (ausência de renda, precário ou nulo acesso aos serviços públicos, dentre outros) e/ou fragilização de vínculos afetivos - relacionais e de pertencimento social (discriminações etárias, étnicas, de gênero ou por deficiências, dentre outras). (BRASIL, 2008, p. 34).

Esta modalidade de proteção concretizase por meio da intervenção dos profissionais (assistentes sociais, psicólogos, pedagogos e outros) que se unem em torno de ações que visam potencializar a família como unidade de referência, conforme propõem as diretrizes do SUAS. Em síntese, as diretrizes da política se fazem no sentido de que o CRAS seja um espaço que estimule o protagonismo de seus usuários por meio da oferta de serviços que visam estimular a convivência, a socialização e o acolhimento de famílias cujos vínculos familiares e comunitários não foram rompidos, consideradas situações de menor complexidade.

A proteção social especial (sobre a qual não cabem discussões neste texto), por sua vez, divide-se em duas modalidades: média complexidade e alta complexidade. A proteção social especial de média complexidade ${ }^{3}$ é materializada no Centro de Referência Especializado de Assistência Social (CREAS). O Centro está organizado para atender e acolher

3. A proteção social especial de média complexidade trata-se de uma proposta que pretende ofertar proteção aos indivíduos e famílias que não estão em condições ou enfrentam dificuldades para se protegerem e/ou desenvolverem enquanto unidade familiar, ou seja, espera-se que o CREAS ofereça espaços para fortalecimento dos vínculos afetivos e sociais das pessoas que chegam até esses espaços, por meio dos seguintes serviços: 
situações em que os direitos - sociais, coletivos e individuais - estão ameaçados e/ou violados por omissão ou ação de pessoas ou instituições. Os profissionais do CREAS têm como objetivo a promoção de atenções socioassistenciais aos indivíduos e às famílias que se encontram, de alguma maneira, em situações de risco pessoal e social decorrentes de: abandono, maustratos físicos e/ou psíquicos, violência sexual, cumprimento de medidas socioeducativas, situação de rua, situação de trabalho infantil e outras situações de violação de direitos. Já a proteção social especial de alta complexidade ${ }^{4}$ é acionada nos casos que requerem proteção integral para garantir o atendimento das necessidades básicas - moradia, alimentação, higienização e outras demandas - dos indivíduos que se encontram sem referência, o que pode ocorrer em decorrência de vínculos rompidos, pessoas que foram retiradas de seu núcleo familiar e/ou comunitário e até mesmo vítimas de desastres naturais.

Na perspectiva da proteção social básica, os serviços devem estar presentes em todos os territórios vulneráveis de todos os municípios ${ }^{5}$, disponíveis ao maior número possível de pessoas que se encontram em situações de risco ou vulnerabilidade social ${ }^{6}$, as quais podem ter acesso àqueles serviços a qualquer momento e fazer do CRAS um centro de referência (como o próprio nome já diz). No caso de territórios de baixa densidade demográfica, com espalhamento ou dispersão populacional (áreas rurais, comunidades indígenas, quilombos, calhas de rios, assentamentos, dentre outros), a unidade CRAS deverá estar em local de maior acessibilidade, podendo realizar a cobertura das áreas de vulnerabilidade por meio do deslocamento de sua equipe, caracterizando, assim, a busca ativa ou o CRAS itinerante - objeto de interesse desse artigo.

plantão social; abordagem de rua; cuidado no domicílio; acompanhamento psicossocial; serviço apoio e orientação aos indivíduos e às famílias vítimas de violência; serviço de enfrentamento à violência, abuso e exploração sexual contra crianças e adolescentes e suas famílias; serviço de orientação e acompanhamento de adolescentes em cumprimento de medida socioeducativa de liberdade assistida e de prestação de serviços à comunidade e suas famílias; serviço de habilitação e reabilitação na comunidade das pessoas com deficiência

4. A proteção social especial de alta complexidade é materializada por meio de programas, instituições e serviços do tipo: casa lar, casa de passagem, albergue, abrigos, lar de idosos, família substituta, família acolhedora, medidas socioeducativas restritivas e privativas de liberdade (internação provisória e sentenciada).

5. Para fins de partilha dos recursos da União, estipula-se o número mínimo de CRAS de acordo com o porte (populacional) do município. São os municípios divididos em: de Pequeno Porte l e Il; de Médio Porte; de Grande Porte; e Metrópole (conforme Tabela 1). Esta classificação possibilita estabelecer as ações de proteção social básica e especial de média e alta complexidade, tanto de responsabilidade dos municípios quanto do Estado (BRASIL, 2005)

6. De acordo com a PNAS/2004, as situações de risco ou vulnerabilidade social são decorrentes de: perda ou fragilidade de vínculos de afetividade, pertencimento e sociabilidade; ciclos de vida; identidades estigmatizadas em termos étnico, cultural e sexual; desvantagem pessoal resultante de deficiências; exclusão pela pobreza e/ou pelo acesso às demais políticas públicas; uso de substâncias psicoativas; diferentes formas de violência advinda do núcleo familiar, grupos e indivíduos; e inserção precária ou não inserção no mercado de trabalho - formal e informal. 
Tabela 1 - Mínimos de CRAS por porte de município.

\begin{tabular}{lllll}
\hline $\begin{array}{l}\text { Porte do } \\
\text { município }\end{array}$ & Número de habitantes & $\begin{array}{l}\text { Número } \\
\text { mínimo de } \\
\text { CRAS }\end{array}$ & $\begin{array}{l}\text { Famílias } \\
\text { referenciadas }\end{array}$ & $\begin{array}{l}\text { Capacidade de } \\
\text { atendimento } \\
\text { anual }\end{array}$ \\
\hline $\begin{array}{l}\text { Pequeno Porte I } \\
\text { Pequeno Porte II }\end{array}$ & Até 20 mil habitantes & 1 CRAS & 2.500 & a 50 mil habitantes \\
$\begin{array}{l}\text { Médio Porte } \\
\text { Grande Porte }\end{array}$ & De 50 a 100 mil habitantes & 2 CRAS & 3.500 & 750 famílias \\
Metrópole & De 100 a 900 mil habitantes & 4 CRAS & 5.000 & 1.000 famílias \\
\hline
\end{tabular}

Fonte: Norma Operacional Básica do Sistema Único de Assistência Social (BRASIL, 2005).

Sposati (2006) afirma que, em ambas as modalidades de proteção, os recursos humanos representam o principal instrumento de trabalho para que o sistema funcione. Visto que a assistência social não opera por tecnologias substitutivas, o trabalho social tornase imprescindível para a materialização das diretrizes. De acordo com a Norma Operacional Básica de Recursos Humanos do Sistema Único de Assistência Social (NOB-RH/SUAS), o trabalho social deve ser desenvolvido por meio das equipes de referência, as quais devem ser constituídas por

[...] servidores efetivos responsáveis pela organização e oferta de serviços, programas, projetos e benefícios de proteção social básica e especial, levando-se em consideração o número de famílias e indivíduos referenciados, o tipo de atendimento e as aquisições que devem ser garantidas aos usuários. (BRASIL, 2011, p. 12).

Segundo os dados do Censo SUAS, havia mais de 44 mil trabalhadores compondo as equipes de referências dos CRAS em 2009. Dentre eles, 21.240 possuíam nível superior, sendo o equivalente a $48 \%$ dos profissionais da proteção social básica. Do total dos 44 mil funcionários dos CRAS: 34,3 eram profissionais de nível médio; 21,3\% eram assistentes sociais; 13,3\% eram psicólogos; $12,7 \%$ eram profissionais de nível fundamental; 4,9\% eram pedagogos; $4,7 \%$ eram estagiários que cursavam algum tipo de graduação; e o restante, 8,8\% do total, era composto por advogados, antropólogos, sociólogos, médicos, enfermeiros, fisioterapeutas e terapeutas ocupacionais (BRASIL, 2011). Ao inserir diferentes categorias profissionais, como técnicos de nível superior nas equipes de referência da proteção social básica, a Política Nacional de Assistência Social é concebida como

[...] direito de cidadania, com vistas a garantir o atendimento às necessidades básicas dos segmentos populacionais vulnerabilizados pela pobreza e pela exclusão social. (BRASIL, 2004, p. 68).

Cabe aos profissionais garantir as principais seguranças da política de assistência social: segurança de sobrevivência ${ }^{7}$ (de rendimento e de autonomia), segurança de acolhida e segurança de convívio ou vivência familiar?

7. A segurança de renda é realizada por meio dos programas de transferência de renda convertida em benefícios financeiros, utilizados para garantir os mínimos sociais e a sobrevivência da pessoa e de sua família. Atualmente, existem três grandes benefícios que garantem a segurança de renda: o Benefício de Prestação Continuada (BPC), o Programa de Erradicação do Trabalho Infantil (PETI) e o Programa Bolsa Família (PBF). 
Cruz e Guareschi (2009) destacam que a atuação de diferentes profissionais é um requisito fundamental para a garantia dos direitos dos usuários. No entanto, no campo da definição de estratégias e formulação dos serviços, a política de assistência social irá impor a necessidade de realizar e divulgar estudos, pesquisas, referências e outras teórico-metodológicas, as quais, além de retirar a improvisação como forma de estruturar o atendimento, poderão atender as especificidades locais e regionais dos territórios e dos usuários.

Nessa perspectiva, de acordo com as OrientaçõesTécnicas para oCentrode Referência de Assistência Social-um caderno de orientações lançado pelo Ministério do Desenvolvimento Social em 2009 -, a oferta de serviços do CRAS deve ser planejada (pelos gestores e trabalhadores) de acordo com a leitura e o

[...] conhecimento do território e das famílias que nele vivem, suas necessidades, potencialidades, bem como do mapeamento da ocorrência das situações de risco e de vulnerabilidade social. (BRASIL, 2009, p. 9).

Outra diretriz apontada pela Política Nacional de Assistência Social e pelas Orientações Técnicas para o Centro de Referência de Assistência Social refere-se à centralidade do território como

[...] fator determinante para a compreensão das situações de vulnerabilidade e riscos sociais, bem como para seu enfrentamento. A adoção da perspectiva da territorialização se materializa a partir da descentralização da política de assistência social e consequente oferta dos serviços socioassistenciais em locais próximos aos seus usuários. Isso aumenta sua eficácia e efetividade, criando condições favoráveis à ação de prevenção ao enfrentamento das situações de vulnerabilidade e risco social, bem como de identificação e estímulo das potencialidades presentes no território. (BRASIL, 2009, p. 13).

De acordo com a política de assistência social, a diretriz da territorialização fazse importante no momento em que "é no território que se encontram as potencialidades para o enfrentamento destas desigualdades" (BRASIL, 2009, p. 13). Outra diretriz igualmente fundamental à ação dos profissionais diz respeito à realização da busca ativa no território de abrangência do CRAS.

A busca ativa refere-se à procura intencional,
realizada pela equipe de referência do CRAS,
das ocorrências que influenciam o modo de
vida da população em determinado território.
(BRASIL, 2009, p. 29).

Com o lançamento do Plano Brasil Sem Miséria, no dia dois de junho de 2011, o governo lançou a meta de retirar 16,2 milhões de brasileiros da situação de extrema pobreza. Para tanto, o plano contempla um conjunto de ações que envolve a criação de diferentes programas e a ampliação de iniciativas já existentes, sempre em parcerias com estados, municípios, empresas públicas e privadas, além de organizações da sociedade civil. O plano é divido em três eixos: transferência de renda; acesso a serviços públicos nas áreas de educação, saúde, assistência social, saneamento e energia elétrica; e inclusão produtiva.

De acordo com a ministra do Ministério do Desenvolvimento Social (MDS), Tereza Campello, o objetivo do plano é aumentar as condições de bem-estar e a renda da população,

8. A segurança de acolhida e segurança de convívio opera com a provisão das necessidades humanas advindas de situações materiais e subjetivas, ou seja, necessidades que começam com os direitos à alimentação, ao vestuário e a um local para dormir. Outra situação que pode demandar acolhida, nos tempos atuais, é a necessidade de separação da família, em decorrência de múltiplas situações, como a "violência familiar ou social, drogadição, alcoolismo, desemprego prolongado e criminalidade [...] além da profunda destituição e abandono que demandam tal provisão" (BRASIL, 2008, p. 32). 
por meio de iniciativas que irão localizar e incluir, através da busca ativa, as famílias extremamente pobres nos diversos programas contemplados pelo plano. Segundo a ministra, a partir de agora, não será a população pobre que terá de correr atrás do Estado, mas o contrário. Para tanto, o governo seguirá os mapas de extrema pobreza produzidos pelo Instituto Brasileiro de Geografia e Estatística (IBGE), e os pontos de atendimento dos programas englobados pelo Brasil Sem Miséria serão os CRAS em funcionamento pelos municípios de todo o país.

Desse modo, o Plano Brasil Sem Miséria lança um foco especial sobre a diretriz da busca ativa como parte fundamental para a superação da pobreza extrema no Brasil. Corroborando essa perspectiva, aos 16 de setembro de 2011, o Conselho Nacional de Assistência Social aprovou a Resolução no 26, que "aprova os critérios para expansão 2011 do cofinanciamento federal, nos serviços de proteção social básica, apresentados pela SNAS". A referida resolução pactua critérios, prazos e procedimentos para expansões qualificadas no âmbito de ações do Programa de Atenção Integral à Família (PAIF), por meio de ações executadas por equipes volantes vinculadas ao CRAS, no qual a primeira atribuição dos profissionais de referência é localizar as famílias que se encontram fora das políticas sociais e incluí-las no sistema de proteção social, de modo a auxiliar na travessia da exclusão para o direito.

[...] o objetivo da Equipe Volante é prestar serviços de Proteção Social Básica no território de abrangência do CRAS e a que se vincula às famílias a ele referenciadas, potencializando o PAIF em territórios de extensão territorial, isolamento, áreas rurais e difícil acesso. A especialidade das Equipes Volantes é prioritariamente ampliar o acesso da população em situação de extrema pobreza dos serviços socioassistenciais de Proteção Social Básica. (BRASIL, 2011, p. 2-3).

Em 25 de outubro de 2011, o MDS publicou a Instrução Operacional Conjunta SENARC/SNAS/MDS no 10 para orientar os municípios sobre o estabelecimento de parcerias para a realização da busca ativa, uma vez que, com o lançamento do Plano Brasil Sem Miséria, o grande intento da assistência social fundamenta-se em tal perspectiva, "que significa levar o Estado até onde o cidadão está, e não esperar que ele venha até o poder público" (BRASIL, 2011, p. 1). Todas as diretrizes destacadas até o momento denotam que a atual configuração da política de assistência social, orientada pela lógica do direito, requer novos modelos, processos, mecanismos e instrumentos para sua operacionalização. A partir desse novo paradigma, mudanças fundamentais têm demandado, igualmente, o comprometimento de todos os atores que operam nessa política, exigindo-lhes novos conhecimentos, atitudes e habilidades para que uma nova forma de assistência social seja pensada e executada. Trata-se de um processo que recai diretamente sobre a dimensão teórico-metodológica e técnico-operativa dos profissionais - técnicos e gestores - que desenvolvem os serviços.

Considerando que o SUAS imprimiu novos rumos e modelos de intervenção junto à população brasileira em situação de vulnerabilidade, requisitando uma perspectiva em que os entes federados devem, gradativamente, assumir maiores responsabilidades, no que se refere à oferta de proteções, surgem, naturalmente, alguns questionamentos: frente a tais diretrizes, quais são as possibilidades de intervenção em nível municipal? O que tais diretrizes, executadas por profissionais de diferentes categorias, podem proporcionar aos sujeitosbeneficiários da política de assistência social e do Centro de Referência de Assistência Social?

$\mathrm{Na}$ tentativa de materializar a maior parte das diretrizes anteriores é que se concebeu a proposta de realizar o "Projeto 
CRAS Itinerante" no município de Coronel Xavier Chaves, Minas Gerais. O projeto consistiu no deslocamento de parte da equipe de profissionais do CRAS até as comunidades rurais e a todos os bairros da zona urbana do município, ofertando serviços para crianças, adolescentes, adultos e idosos - conforme descrição, abaixo, do trabalho desenvolvido.

\section{Coronel Xavier Chaves e o CRAS Itinerante}

O município de Coronel Xavier ChavesMG localiza-se na região Campos das Vertentes, próximo a São João Del Rei (aproximadamente 12 quilômetros) e Tiradentes (aproximadamente 20 quilômetros). Ambas as cidades são históricas com forte predominância da economia voltada ao setor turístico e à produção de artesanato.

Se comparada às demais cidades da região, Coronel Xavier Chaves não possui o mesmo potencial para a exploração do turismo, uma vez que as opções turísticas restringemse a uma igreja de pedra construída no século XVIII, um engenho de cachaça (considerado o engenho familiar mais antigo do Brasil), que pertenceu à família de Tiradentes, e uma árvore da espécie jequitibá, considerada a maior e mais antiga da região, além de algumas casas coloniais e a tradicional hospitalidade mineira.

A economia do município é baseada na agropecuária, na prestação de serviços e na produção de artesanato, sobretudo esculturas em pedra gnaisse. O município não possui indústrias, fazendo com que o mercado de trabalho seja limitado a pouquíssimas oportunidades. Essa realidade faz com que muitos moradores busquem trabalho nas cidades vizinhas, como São João Del Rei, Prados, Tiradentes, Ritápolis, Resende Costa e até mesmo Lagoa Dourada.

De acordo com os dados do Instituto Brasileiro de Pesquisa e Geografia (IBGE), divulgados pelo Censo 2010, atualmente, a população xavierense é estimada em 3.301 pessoas, sendo 1.645 homens e 1.656 mulheres.
Desse total, 1.800 pessoas vivem na zona urbana, enquanto 1.501 vivem na zona rural, divididos em, aproximadamente, 9 comunidades rurais e alguns pequenos povoados. A partir dos dados supracitados, constata-se que 54,52\% da população são moradores da zona urbana e 45,48 da zona rural. Os dados também apontam que a incidência da pobreza é de 30,88\%.

O município possui diversas comunidades rurais, e os moradores de tais comunidades enfrentam inúmeras dificuldades para acessar a zona urbana e usufruir dos serviços públicos (não há transporte público e a maior parte dos moradores da zona rural não possui automóvel), o que os levam a depender de carona, pagar táxi ou, então, enfrentar verdadeiras maratonas de caminhada pelas estradas de terra. Considerando esse fato, o deslocamento de parte da equipe de referência do CRAS até as comunidades rurais foi avaliado como uma possibilidade de facilitar o acesso da população às informações e aos serviços de assistência social, além de desenvolver um trabalho social de modo descentralizado e participativo. Basicamente, foi a partir de tais premissas que nasceu a ideia do projeto CRAS Itinerante.

Outro fator que sustentou a necessidade de realizar o projeto foi o fato de muitas pessoas no município, sobretudo os moradores da zona rural, não conhecerem ou não saberem da existência do CRAS, uma vez que sua inauguração ocorreu no final do mês de março de 2011 e a execução do projeto aconteceu no mês de julho do mesmo ano. Sabendo que a maior parte da população rural não estaria informada sobre as atribuições do CRAS (em termos de serviços, orientações, projetos e profissionais), um dos objetivos da proposta foi a divulgação de sua estrutura, funcionamento, equipe de referência, projetos, programas e serviços disponíveis à população, bem como o acesso a direitos sociais. A proposta do CRAS Itinerante estruturou-se, basicamente, em quatro eixos: divulgação da inauguração do CRAS; realização 
da busca ativa, por meio do mapeamento das demandas de cada comunidade e seus moradores; identificação das potencialidades dos habitantes, convidando-os a participar da estruturação dos serviços que eles próprios desejassem; disponibilização de serviços para crianças e adolescentes de 3 a 17 anos de idade; e, principalmente, orientação da população acerca de seus direitos - serviços e benefícios.

\section{Objetivos}

a. Realizar a busca ativa no território, de modo a identificar as vulnerabilidades e as potencialidades de cada território;

b. Divulgar o CRAS (estrutura, funcionamento, equipe de referência, projetos, programas e serviços disponíveis) aos moradores do município, de modo a promover a apresentação e integração entre os profissionais do CRAS e a população do município;

c. Facilitar o acesso da população a alguns de seus direitos sociais;

d. Desenvolver (e experimentar) uma metodologia de trabalho social de caráter descentralizado e participativo;

e. Oferecer um espaço lúdico e educativo para crianças e adolescentes em seu próprio território.

\section{Metodología}

Após algumas reuniões entre a equipe da Secretaria Municipal de Assistência Social e a equipe de referência do CRAS, definiu-se que o melhor período para desenvolver a proposta seria o mês de julho. Assim, estabeleceu-se que o CRAS Itinerante visitaria as comunidades das 13h às 16h, obedecendo o cronograma a seguir, com as datas e as respectivas comunidades: 14/07 - Pinheiros; 15/07 - Cachoeira; 18/07 - São Caetano; 19/07 - Capoeirinha; 20/07 - Olhos D’agua; 21/07 - Planalto de Fátima; 22/07 - Agua Limpa; 25/07 - Invernada; 26/07 - Barreiro; 27/07 - Vila Fátima; 28/07 - Vila Mendes; 29/07 - Centro da cidade. Sobre os locais em que o projeto foi desenvolvido, cabe mencionar que todas as comunidades rurais em questão possuem edificações comumente chamadas de salão social ou centro social. Tais edificações consistem em antigas escolas rurais que, gradativamente, foram sendo desativadas e transferidas para a zona urbana do município. Atualmente, a única finalidade desses salões é serem espaços para a realização de consultas médicas, com um médico clínico geral, e para comemorações de algumas datas festivas (geralmente ligadas a santos e padroeiros).

Na semana anterior à realização do projeto, a equipe do CRAS visitou os salões para fazer um levantamento sobre suas condições de uso e infraestrutura. Os profissionais tomaram nota dos recursos e materiais necessários (específicos para cada salão) para a execução das atividades, tais como: materiais de limpeza, copos descartáveis, água, papel higiênico etc. Durante as visitas, a equipe do CRAS estabeleceu contatos e parcerias com os moradores locais para que eles pudessem ajudar na divulgação do projeto e no preparo e limpeza do local para a realização das atividades, já incitando a população para a participação popular e comunitária. Definiu-se que o projeto levaria as seguintes atividades até as comunidades:

a. Plantão social para mães, mulheres, adultos, idosos e pessoas portadoras de deficiência. De modo geral, o plantão social (realizado pela coordenadora do CRAS e pelo Secretário Municipal de Assistência Social) seria para: divulgar o CRAS e seus serviços, programas, 
projetos, atribuições e finalidades; realizar o referenciamento das famílias; prestar orientações sobre direitos, benefícios e programas, como o Benefício de Prestação Continuada (BPC), o Programa Bolsa Família (PBF) e outros benefícios previdenciários. A atividade seria realizada por meio de intervenções individuais e coletivas, a depender do número de participantes de cada comunidade, bem como as demandas por eles apresentadas.

b. Brinquedoteca para crianças de 3 a 6 anos. Para tal, definiu-se que a brinquedista levaria parte da brinquedoteca para oferecer atividades lúdicas e pedagógicas às crianças da faixa etária em questão. Assim, as crianças ficariam ocupadas com atividades pedagógicas enquanto seus pais e mães participassem do plantão social.

c. Transformação de Sucata para crianças de 7 a 10 anos. Basicamente, a atividade (realizada por uma pedagoga) consistiria na transformação de materiais recicláveis (garrafas $\mathrm{PET}$, caixas de pasta de dente, caixas de sabonete, sabão em pó, latas de achocolatado, latas de extrato de tomate, e outros diversos materiais usualmente descartados pela população) em brinquedos, visando resgatar a imaginação das crianças e fortalecer a consciência ambiental delas, uma vez que, atualmente, grande parte das preocupações mundiais diz respeito a iniciativas que prezem a sustentabilidade do planeta. Destaca-se que, após a realização da atividade, as crianças poderiam levar os brinquedos produzidos para casa.

d. Oficina de Teatro para adolescentes de 11 a 17 anos. De modo geral, as oficinas (realizadas por uma graduanda de artes plásticas) seriam para a realização de exercícios de apresentação e improvisação; técnicas de relaxamento; dinâmicas de interação, socialização, oratória, entre outras. Durante as oficinas, a oficineira abordaria temas como: sexualidade, família, trabalho e outras categorias de discussão que, possivelmente, surgiriam nos grupos.

Após a definição das atividades, do cronograma, dos locais, dos profissionais e da metodologia a ser empregada no trabalho social com as famílias, recorremos à Secretaria Municipal de Saúde no intuito de solicitar a cooperação dos agentes comunitários e estabelecer uma parceria. Desse modo, os agentes contribuíram na divulgação da proposta para a população local de cada comunidade, entregaram as fichas para inscrição das crianças e adolescentes nas atividades ofertadas e colaboraram com o fornecimento de informações úteis sobre alguns moradores e situações pontuais de cada território visitado.

Para a divulgação da proposta, também foram utilizadas outras estratégias, dentre as quais se destacam: cartazes afixados em locais públicos, tais como Prefeitura, Câmara Municipal, supermercados e lojas; anúncios na rádio local e no alto-falante da igreja matriz da cidade; panfletos distribuídos aos alunos da Escola Municipal e Escola Estadual e pais, além de outras formas de divulgação do trabalho que estaria por vir.

Em síntese, os profissionais pretendiam chegar até as comunidades, realizar uma breve conversa em grupo, explicar as intenções e os objetivos do CRAS Itinerante e, depois, dividir as turmas para cada atividade específica. Enquanto a assistente social realizaria os atendimentos, as crianças participariam das atividades lúdicas e pedagógicas. 


\section{Considerações finais}

Considerando que as necessidades são ditadas pelo território e que apenas por meio do conhecimento de suas características é que se pode saber que serviços deverão ser ofertados; que ações socioassistenciais, desenvolvidas; que atenções, necessárias; quais objetivos se quer atingir; qual metodologia adotar; onde serão ofertados, com que frequência e qual a sua duração, o projeto CRAS Itinerante foi interessante para a constatação de algumas realidades.

Os resultados alcançados pelo foram extremamente valiosos por vários motivos. $\mathrm{O}$ primeiro efeito positivo da proposta foi o alcance e o atendimento de todas as comunidades rurais do município. O deslocamento da equipe de referência até as comunidades transportou não só os profissionais envolvidos no projeto, mas também diversas proteções e atenções, ao passo que a população obteve acesso a importantes informações sobre os seus direitos, dentre eles: benefícios regulamentados por legislação municipal, como auxílio funeral, auxílio natalidade, padrão de energia elétrica e programa de reformas habitacionais; benefícios da previdência e assistência social, como o Bolsa Família, o Benefício de Prestação Continuada e outros; e serviços do CRAS já implantados, bem como a possibilidade de implantação de outros em parceria com as comunidades.

Cabe mencionar que, antes da inauguração do CRAS, a Secretaria Municipal de Assistência Social (SMAS) era composta apenas por duas pessoas: o Secretário Municipal de Assistência Social e um técnico administrativo. Com uma equipe profissional extremamente reduzida, as ações da SMAS limitavam-se ao atendimento das demandas mais urgentes da população, usualmente, a busca por benefícios eventuais e o atendimento/acompanhamento de algumas poucas famílias. As atribuições do secretário municipal acabavam por se misturar à função de gestor e técnico da política, por meio da realização de plantão social, visitas domiciliares, acolhimento dos usuários, referenciamento das famílias, orientações sobre benefícios, encaminhamentos, elaboração de relatórios para o Programa Bolsa Família, atribuições na Secretaria Estadual de Desenvolvimento Social (SEDESE) e no Ministério de Desenvolvimento Social (MDS), elaboração de ofícios, prestação de contas e demais trabalhos, gerando sobrecarga de trabalho e, consequentemente, prejuízo no que diz respeito ao tempo disponível para o atendimento da população que recorria à assistência social. Com a inauguração do CRAS, ampliouse a equipe de profissionais da SMAS com a contratação de mais um assistente social, uma pedagoga, dois psicólogos e alguns oficineiros. Com isso, expandiu-se, automaticamente, a capacidade funcional de planejamento e execução das ações, serviços, benefícios, projetos e programas do setor.

Na ocasião do projeto, o deslocamento da equipe de profissionais possibilitou a realização de uma divulgação básica e introdutória sobre o que é o CRAS, os novos profissionais que passaram a compor a política municipal de assistência social, os novos serviços, programas e projetos já em andamento e, também, o levantamento das demandas para futuras ações da assistência social, construídas junto aos usuários que participaram do projeto.

Em síntese, convém ressaltar que o CRAS Itinerante proporcionou um contato direto dos novos direcionamentos da política de assistência social com os moradores das comunidades, por meio da apresentação e da aproximação entre a população e os profissionais do CRAS. No mesmo sentido, a iniciativa permitiu que os profissionais conhecessem os usuários e o território, ocasião em que foi possível realizar um levantamento das demandas individuais e coletivas. Por intermédio do atendimento social, foi possível realizar, ainda que de modo 
sintético, um mapeamento das demandas de cada comunidade e bairro do município, as dificuldades enfrentadas por algumas famílias e, sobretudo, as situações de vulnerabilidade social de alguns moradores.

Por tudo isso, constata-se que a proposta alcançou alguns objetivos, tanto da política de assistência social como do projeto, visto que a busca ativa realizada possibilitou identificar as situações de maior vulnerabilidade e risco social, além de ampliar o conhecimento e a compreensão acerca da realidade social. O projeto também contribuiu para o conhecimento da dinâmica do cotidiano das populações locais, isto é, a realidade vivida pela família, sua cultura, seus valores, as relações estabelecidas dentro e fora do território, bem como os apoios e recursos existentes.

Nesse sentido, além do mapeamento sobre as dificuldades enfrentadas pela população local e pelos territórios, o CRAS Itinerante proporcionou um momento em que foi possível realizar um prévio levantamento das demandas e identificar as potencialidades de cada comunidade. Também foi possível conhecer de perto o espaço socioterritorial, identificar as lideranças locais e conhecer o espaço físico de cada salão comunitário.

Em linhas gerais, descreveremos algumas constatações realizadas durante o CRAS Itinerante, as ações que já estão em fase de execução e outras em fase de planejamento, ações essas pensadas e construídas em sintonia com a iniciativa e por meio do contato direto dos profissionais com a realidade observada.

Algumas comunidades manifestaram interesse em reativar a associação de moradores, que, até então, encontravam-se inativas. Dessa forma, após a realização da proposta, ocorreram encontros com os moradores da comunidade, que receberam as orientações sobre como proceder com a documentação necessária para regularizar a associação. Em alguns casos, a equipe do CRAS acompanhou as etapas das assembleias, formação da diretoria, regularização da documentação necessária para inscrição no Conselho Municipal de Assistência Social (CMAS) e na Secretaria Estadual de Desenvolvimento Social (SEDESE).

Em outras comunidades, a maior reivindicação dos moradores envolveu a categoria trabalho e inclusão produtiva. Diante da escassez de oportunidades de trabalho, somada às dificuldades de transporte e de locomoção até o município de Coronel Xavier Chaves (ou para os municípios da região), a população encontrase "engessada" a qualquer tipo de acessibilidade ao mercado de trabalho, formal ou informal.

Numa comunidade específica, cuja realidade apresenta elevadas taxas de alcoolismo, a assistente social do CRAS diagnosticou a necessidade de realizar atividades esportivas e cursos profissionalizantes para os jovens, uma vez que há muitos adolescentes em situação de "ócio" ou inserção informal no mercado de trabalho.

Em outra comunidade bastante específica, além das atividades com crianças e adolescentes, predominaram os atendimentos a alguns idosos que buscaram orientações sobre benefícios previdenciários; assim, a assistente social prestou as informações mais imediatas e solicitou que os interessados procurassem o CRAS em outra ocasião, para que, num momento posterior, eles pudessem receber o devido encaminhamento para a previdência social.

Em diversas comunidades, foi possível identificar alguns casos isolados de violência física, violência psicológica, maus-tratos e negligência contra crianças e idosos. Nesses casos, as famílias foram referenciadas e, no momento, já estão sendo acompanhadas pela equipe de profissionais do CRAS.

É interessante observar que, nas três comunidades (bairros) da zona urbana, praticamente não houve adultos que participaram da proposta, fato que foi avaliado pela equipe com normalidade, pois, acredita- 
se, que os moradores da zona urbana já conhecem e estão mais habituadas com o CRAS, seus profissionais e seus serviços. De modo geral, predominaram as solicitações de benefícios eventuais, orientações de benefícios previdenciários e o apoio para formação e fortalecimento de associações comunitárias. Assim, a iniciativa do CRAS Itinerante foi extremamente eficaz e viável por várias razões, sobretudo pelo baixo custo de sua realização e pela quantidade de informações trocadas entre os usuários da política e a equipe da SMAS.

No momento em que o CRAS, por meio de sua equipe de profissionais, deslocou-se até a população, houve, nitidamente, a valorização do espaço territorial como unidade imprescindível na formulação e no planejamento de ações, programas, projetos e serviços da política de assistência social. $\mathrm{O}$ pressuposto trabalhado pela equipe foi o de que o território é o "chão duro" de muitas realidades, mas, também, o "terreno fértil" para muitas possibilidades.

\section{Referências}

AFONSO, M. L. M. O papel do psicólogo no Centro de Referência de Assistência Social. In: CONGRESSO DE PSICOLOGIA E DIREITOS HUMANOS, 1., 2009, Belo Horizonte. mimeo.

BRASIL. Constituição 1988. Constituição da República Federativa do Brasil. Brasília, DF: Senado Federal, 1998.

Lei Orgânica da Assistência Social. Lei no 8.742, de 7 de dezembro de 1993. Dispõe sobre a organização da assistência social e dá outras providências. Brasília, DF: Senado Federal, 1993.

. Ministério do Desenvolvimento Social e Combate à Fome. Política Nacional de Assistência Social. Brasília, DF: MDS, 2004.

. Ministério do Desenvolvimento Social e Combate à Fome. Norma Operacional Básica NOB/SUAS. Brasília, DF: MDS, 2005.

- Ministério do Desenvolvimento Social e Combate à Fome. Política Nacional de Assistência Social. São Paulo: Cortez, 2008.

- Ministério do Desenvolvimento Social e Combate à Fome. Orientações Técnicas: Centro de Referência da Assistência Social - CRAS. Brasília, DF: MDS, 2009.

Ministério do Desenvolvimento Social e Combate à Fome. Protocolo de gestão integrada de serviços, benefícios e transferências de Renda no Âmbito do Sistema Único de Assistência Social. Brasília, DF: MDS, $2009 b$.

Ministério do Desenvolvimento Social e Combate à Fome. Censo SUAS 2009. Brasília, DF: $\overline{\text { MDS, }} 2011$.

. Ministério do Desenvolvimento Social e Combate à Fome. Instrução Operacional Conjunta SENARC/SNAS/MDS no 10. Brasília, DF: MDS, 2011 b. 
. Conselho Nacional de Assistência Social. Resolução n² 26, de 16 de setembro de 2011. Aprova os critérios para expansão 2011 do cofinanciamento federal, nos serviços de proteção social básica, apresentados pela SNAS. Diário Oficial da União, Brasília, DF, 19 set. 2011.

CRUZ. L. R. da C.; GUARESCHI, N. (Orgs.). Políticas públicas e assistência social: diálogos com as práticas psicológicas. Petrópolis, RJ: Vozes, 2009.

LOPES, M. H. C. O tempo do SUAS. Serviço Social \& Sociedade, São Paulo, v. 87, p. 76-95, 2006.

SPOSATI, A. O primeiro ano do sistema único de assistência social. Serviço Social \& Sociedade, São Paulo, v. 87, p. 96-122, 2006.

Submetido em 8 de março de 2014.

Aprovado em 26 de março de 2014. 